\title{
Effects of conflict, displacement, and migration on the health of refugee and conflict-stricken populations in the Middle East
}

\author{
Selma Nouri \\ Research Intern, University of Maryland School of Public Health Science, US
}

\begin{tabular}{l}
\hline Article Info \\
\hline Article history: \\
Received Jun 3, 2019 \\
Revised Aug 12, 2019 \\
Accepted Aug 30, 2019 \\
\hline
\end{tabular}

\section{Keywords:}

Communicable diseases

Mental health

Neonatal health

Non-communicable diseases

Refugee health crisis

\begin{abstract}
The global refugee crisis has reached an all-time high, with over 68 million innocent people forced to flee their homes due to violence, famine, governmental instability, or genocide. As a result of the struggles and traumas encountered by war and migration, millions of refugees suffer from acute and life-threatening physical and mental health illnesses. However, these diseases and internal-battles are often overlooked, leaving most conflict-stricken countries and refugee camps ill-equipped and unable to cope. Rather than settling into more humane and healthy living conditions, upon migration, most refugees are faced with realities that deny them a dignified and fulfilling life. More often than not, refugee camps and host countries accommodate a deplorable lifestyle that provides minimal and inadequate health-care, extreme and life-threatening poverty, and inhumane and unsanitary living conditions-exasperating the rate and risk of morbidity and mortality amongst refugee populations. This research paper aims to analyze the harsh conditions that refugees and conflict-stricken populations are currently forced to endure, as well as the effects of those conditions on the spread of communicable and non-communicable diseases, the development and growth of neonatal disorders, and the overall rise in mental illness. The paper also aims to suggest specific measures that can be taken in order to prevent the increase in morbidity and mortality rates amongst vulnerable refugee populations and recommend steps that international bodies and non-governmental organizations can take in order to solve the refugee health crisis.
\end{abstract}

Copyright @ 2019 Institute of Advanced Engineering and Science. All rights reserved.

\section{Corresponding Author:}

Selma Nouri,

Research Intern, Department of Public Health Science,

University of Maryland School of Public Health,

4200 Valley Dr, College Park, MD 20742.

Email: sn3qy@virginia.edu

\section{INTRODUCTION}

Risking to embark on a fatal and treacherous journey by sea, in 2015, over 900,000 innocent families landed on the beaches of Italy and Greece in the hopes of finding a safe and stable home [1]. This was only the beginning of what the UNHCR has deemed to be the largest humanitarian crisis since World War 2, with over 68.5 million refugees worldwide- all in search of safety, stability, and hope [2]. In part, this upsurge in migration and displacement was the result of a movement in 2011, known as the Arab Spring, which inspired several Arab nations to remove corrupt, dictatorial leaders and establish democracy [3]. However, many of these peaceful and optimistic pursuits resulted in countless government failures and violent civil wars that gave birth to a number of terrorist groups and allowed international bodies to take advantage of internal weakness and instability in the Middle East.

The on-going civil war in Syria, raging for nearly seven years, has taken over 400,000 innocent lives and has resulted in the displacement and migration of over 11 million people [4]. However, prior to the civil 
war, Syria was a flourishing state with one of the best healthcare systems in the Middle East. In 2012, the average life expectancy had reached 75.7 years [5], and the infant mortality rate had reached a record low of 17.9 deaths per 1,000 live births [6].

In addition, the Syrian pharmaceutical industry was extremely prosperous-nine out of every ten pharmaceuticals and medicines provided by Syrian clinics were manufactured by the country's inherent pharmaceutical industry [7]. However, the country's ongoing civil war has reversed the once flourishing health care system. Since the onset of the civil war, the average life expectancy in Syria has fallen to 64.5 years for both males and females [8]. Additionally, over $50 \%$ of the country's physicians and medical professionals have fled, over $60 \%$ of Syrian hospitals and medical facilities have been destroyed or rendered useless [9], and the once internationally prosperous pharmaceutical industry has become obsolete, with the drug production rate decreasing by nearly $90 \%$ [7].

These circumstances have inevitably resulted in the resurgence of, once eradicated, life-threatening diseases and have allowed for a severe increase in both communicable and non-communicable diseases, mental health disorders, and neonatal diseases and defects. Once, easily treatable diseases have now become long and painful death sentences. As Whitehall Correspondent for The Independent, Charlie Cooper, stated "Syria is the first state ever to have fully established a fully functioning, highly effective, 21 st-century healthcare system and then seen it collapse [7]."

This severe breakdown in the overall healthcare status and system in Syria is caused by the population's direct exposure to violence, brutality, and unsanitary conditions. Over 6 million Syrian children are constantly exposed to death, forced brutality, family separation, forced child recruitment, sexual harassment, and pollution. Additionally, over three million homes have been destroyed and over half of the medical and educational facilities in Syria have been demolished. As a result, over 9 million Syrians are out of work or school, which has resulted in a collective shortage of vital skills, a rise in extreme poverty, and an increase in critical mental health diseases and disorders [10].

Along with the relentless demolition, there has been a life-threatening lack of sanitation and hygienic care. The distribution of infected and polluted water and food has rapidly increased the spread of disease and has drastically increased the overall death rate. And with a lack of medical professionals, pharmaceuticals, and health care centers, millions of Syrians are unable to cure easily treatable diseases and infections, resulting in unnecessary amputations and preventable deaths.

Similarly, the civil war in Yemen has taken over 50,000 innocent lives and has resulted in the displacement and migration of over 3 million people [11]. The ongoing conflict, which spurred in 2015, has resulted in a severe health epidemic due to inhume and unsanitary conditions, severe famine, and relentless violence. Unlike Syria, prior to the civil war, Yemen was the poorest state in the Middle East. Consequently, war has only made matters worse. With a majority of the population in the final stages of famine, and over one million people infected with the life-threatening cholera disease, the United Nations has declared the situation in Yemen to be the world's largest humanitarian crisis [12]. Over 22 mil- lion Yemenis are in need of food assistance and over 8.4 million are in the final stages of malnutrition [12]. This severe state of hunger and malnutrition has inevitably weakened the immunity and internal systems of the Yemeni people, in- creasing susceptibility to life-threatening diseases and disorders. Rather than assisting this innocent and vulnerable population, international bodies have only made matters worse through excessive bombing and air strikes. These actions have resulted in the destruction of homes and medical centers, the spread of life-threatening chemical toxins and pollution, the restriction of food and fuel imports, and the furtherance of malnutrition. Furthermore, a lack of governmental and foreign aid has resulted in the astringent spread of unsanitary conditions, which have contributed to the lethal cholera outbreak. Alongside the rubble and debris, garbage and sewage fill the streets of Yemen. This pollution acts as a breeding ground for life-threatening bacteria and pathogens, directly exposing the non-immunized and weak internal systems of the Yemeni people to lethal diseases and disorders. Additionally, over two-thirds of the Yemeni population does not have access to clean water. The aggregation of these conditions in Yemen has contributed to the severe increase in life threatening communicable and non-communicable diseases, mental illnesses, and neonatal disorders.

Typically, those living in an area of conflict are either left displaced within the conflict or are confronted with the dreadful enterprise of migration. After encountering brutal conditions at home, most refugees are generally not welcomed into improved, or in any way, humane conditions in the host countries and refugee camps. Upon arriving, refugees are con- fronted with unsanitary, dangerous, and inhumane living conditions. Most of the camps are overpopulated and exceed capacity by over one thousand people, making the combination of overpopulation and unsanitary conditions a breeding ground for life-threatening diseases and viruses. As follows, this overpopulation allows for the rampant proliferation and spread of disease, and makes the eradication of these easily treatable diseases nearly impossible. Volunteers in a refugee camp in Calais, France, noted that the camp "was infested with rats, the water was 
contaminated with feces, and tuberculosis was rampant [13]." Similarly, refugee camps in Greece were reported to have an absence of running water and electricity, resulting in many refugees freezing to death [14]. The UNHCR also noted that in refugee camps in Moria, Greece, sexual assault is "rampant [13]," not only resulting in an increase in the spread of communicable diseases but an increase in the diagnosis of mental health disorders. According to the International Organization for Migration, the attempted suicide rate in refugee camps is three times the global average. Additionally, there has been a noticeable in-crease in the rates of anxiety, PTSD, and depression amongst displaced and refugee populations [13].

It is crucial that international bodies and non-governmental organizations work to relieve the brutality and adversity faced by both displaced and refugee populations in the Middle East. These frivolous conflicts are destroying the lives of innocent human beings who are simply in search of hope, safety, and humanity. Having endured relentless brutality and pain, the least we can do is provide them with sanitary, safe, and humane living conditions and an equal opportunity to fundamental healthcare. The goal of this research paper is to analyze the harsh conditions that refugees and conflict- stricken populations are currently forced to face, as well as the effects of those conditions on the spread of communicable and non-communicable diseases, the development and growth of neonatal disorders, and the overall increase in mental health diseases. This paper also aims to suggest specific measures that can be taken in order to prevent this rise in mental and physical health issues amongst these vulnerable populations and recommend steps that international bodies and non-governmental organizations can take in order to solve the refugee health crisis.

\section{RESEARCH METHOD}

Explaining research chronological, including research design, research procedure (in the form of algorithms, Pseudocode or other), how to test and data acquisition [1-3]. The description of the course of research should be supported references, so the explanation can be accepted scientifically [2, 4].

A systematic search, as well as, a compilation of literature was gathered in order to analyze the prevalence, impact, risk factors, implications, current prevention tactics, and recommendations regarding the current toxic state of mental health, communicable and non-communicable diseases, and neonatal disorders amongst refugees and conflict-stricken populations in the Middle East. The main regions of conflict that this paper focuses on are Syria and Yemen.

A prevalent amount of data and analytical research was compiled from a number of published sources including, scientific journals, analytical reports, WHO (World Health Organization) health reports and statistics, World Bank data, reliable articles, scientific databases, and scientific archives. This paper draws on a number of reputable and highly regarded secondary sources, as well as both qualitative and quantitative data, in order to provide effectual primary recommendations and potent research.

Through these findings, this paper analyzes the harsh conditions that conflict-stricken populations and refugees in the Middle East are forced to face and the correlation between those conditions to the overall rise in poor health, primarily focusing on the rise in mental health issues, communicable and non-communicable diseases, and neonatal disorders. The compilation of over 40 sources of literature, data, and archived reports were also used to develop primary and essential recommendations that non-governmental organizations and international bodies could use in order to ameliorate this ever-growing health crisis and relieve these vulnerable populations.

\section{RESULTS AND DISCUSSIONS}

\subsection{Increasing mental health diseases and disorders}

a. How have war, conflict, and migration increased the risk of mental health disorders and diseases amongst vulnerable populations in the Middle East?

b. What measures can be taken in order to effectively ameliorate the increasing mental health crisis amongst conflict-stricken and refugee populations in the Middle East?

With the rise of conflict, migration, and displacement in the Middle East, there has been an exceedingly apparent in- crease in the rates of mental health diseases and disorders amongst those living in refugee camps and conflict-stricken regions such as Syria, Iraq, Palestine, and Yemen. Exposure to violence and conflict has widened the range of mental health issues evolving amongst these vulnerable populations. Consequentially, the effects have been especially evident amongst children and teens who have been exposed to conflict and displacement since birth.

Within the past seven years, there has been an exacerbation of pre-existing mental health disorders and a surge in the detection and diagnosis of unfamiliar mental health diseases and disorders. Evidently, 
these increasing rates can be directed towards the refugee and conflict-stricken population's exposure to death, violence, severe trauma, inhumane living conditions, proximity to chemical toxins, and relentless fear [15]. A study carried out by the International Organization for Migration (IOM), between November 2007 and January 2008, found that when assessing over 800 Iraqi refugees, in both Lebanon and Jordan, "more than half of those interviewed" were suffering from high emotional and psychological distress-"distress factors including panic attacks, anger, tiredness, sleep problems, and fears." Additionally, $21 \%$ of those assessed in Jordan and 34\% of those assessed in Lebanon, who had experienced severe distress factors such as the assassination of family and friends, torture, rape, or kidnapping, were found to be suffering from psychological distress that was "overwhelming." The study also found that the "insecurity of their refugee life, a lack of employment and de-professionalization for Iraqis whose qualifications are unrecognized, poor living conditions, and access to health and social services, including education" have contributed to further deteriorating their state of mental health.

Moreover, there was a reported increase in behavioral and learning difficulties amongst refugee children, not only due to violence and displacement but also as a result of "prolonged absence from school" during conflict and displacement [16]. For those who have been unable to flee the prolonged conflict in Syria, many innocent civilians are constantly exposed to direct violence and the life-threatening effects of chemical warfare. This immediate exposure to violence and chemical toxins not only results in a constant mental state of fear and trauma, but can also lead to critical mental health disorders such as PTSD and can disturb the developmental growth process of the brain. A Physician and Epidemiologist at Boston University, Dr. Sandro Galea, stated that the life-threatening repercussions of exposure to harmful chemical agents and toxins has been especially evident amongst the younger generation of Syrian children who were born into direct conflict. Dr. Galea forenamed that the constant chemical attacks will "result in children having reduced capacity for a full range of adult functioning," which in part is, as he mentioned, "changing the developmental trajectory and the potential of a whole generation [17]." Researchers have also distinguished that chemical attacks can both directly and indirectly result in a severe rise in PTSD and depression amongst vulnerable populations. Associate Professor of Population and Family Health and Director of Research for the Program on Forced Migration and Health at Columbia University, Lindsay Stark, stated, "toxic stress affects brain development, learning and the social emotional ability to regulate one's behavior." And although Dr.Stark mentions that children can be extremely resilient, she also notes that the more violence and conflict that these children are exposed to, the harder it can be to thwart off the mental health illnesses, developmental regressions, and severe trauma that they carry with them [17]. This supports the proof that once refugees flee these regions of conflict, camps must be equipped with mental health professionals that are prepared to offer refugees a "sense of normalcy" and an opportunity to rebuild their lives.

A report by the World Health Organization, Mental Health of Populations Exposed to Biological and Chemical Weapons, noted that although some chemical or biological weapons may not induce significant mortality or physical morbidity rates, most, if not all, chemical or biological weapons do engender high rates of severe and life-threatening mental illnesses. The report specifically stated that "as the term bio-terrorism suggests, biological (and chemical) attacks are associated with the experience of intense social or psychological distress, especially fear [18]." This understanding is extremely important when analyzing the intentions behind chemical warfare and bioterrorism, which are not only to murder but to create a sense of social disruption, fear, and mental instability. These intentions were notable when re- searchers found that bombs filled with chlorine and the banned chemical sarin were being dropped on innocent Syrian civilians in April of 2018. The attacks were conducted near heavily populated hospitals and resulted in the loss of many innocent lives, including children. Sarin is a nerve agent that attacks the cholinergic system, which transmits signals between the brain and muscle tissues. Those affected by the agent may undergo paralysis and a series of convulsions that could be life threatening. However, many of those who survive the initial effects will most likely experience a number of permanent mental health issues, such as reduced brain volume, diminished mental function, abnormal brain wave responses, chronic depression, insomnia, and post traumatic stress disorder [19]. The use of inhumane and life threatening chemical and biological agents such as Sarin on innocent civilians should be investigated by both governmental and non-governmental organizations. These harmful agents could impact the mental stability of an entire generation.

As reported by Save the Children, a significant number of Syrian children are currently suffering from severe toxic stress, an activation of the "stress response systems" due to severe and prolonged childhood adversity, which can lead to the underdevelopment of the brain, life-threatening mental health diseases, and cognitive impairment [20]. The report noted that " $78 \%$ of children feel grief and extreme sadness some or all of the time and almost all adults said children had become more nervous or fearful." Additionally, it was found that $51 \%$ of children are turning to substance abuse as a coping mechanism, and $71 \%$ of children are suffering from "bedwetting and involuntary urination." Altogether, the on-going violence and conflict in Syria has resulted in a severe and "constant psychological strain on children" that 
"has manifested itself in bed wetting, involuntary urination in public, speech impediments and children losing the ability to speak altogether, and substance abuse. Communities and professionals also report a rise in self-harm and suicide at- tempts among children as young as 12 [20].”

Similarly, the ongoing conflict and violence in Yemen has resulted in a significant mental health crisis that is not receiving enough attention or care from national or international bodies. A report by Columbia University's Mailman School of Public Health put the entirety of the crisis into perspective, in saying "the many serious implications of the war in Yemen, ranging from the population's frequent exposure to violence to widespread insecurity, food shortages, disease, rampant and accelerating poverty, fractured social ties, and a lack of basic social services have been immense stressors on the population that significantly heighten the threat of widespread deterioration of mental health. A person who is 25 years of age today in Yemen has already lived through 14 other major armed conflicts in his or her lifetime. Many Yemenis have directly or vicariously experienced serious harm and trauma-threats to their lives from armed groups, the disappearance of relatives, airstrikes, arbitrary detainment or tortured, and attacks by non-state actors and militias [21]."

Much of the Yemeni population, including those who are still living in the state of conflict and those who have migrated to refugee camps, is suffering from severe trauma and psychological turmoil. Yet, there are a lack of services, within camps and the country itself; that are tending towards ameliorating the rapidly increasing mental health crisis. Psychologists and mental health experts in Yemen have noted that the suicide rate in the capital increased by nearly 40.5\% from 2014 to 2015 [21]." In comparison to the pre-war period, there is also a significant increase in the number of patients being admitted into psychiatric hospitals and mental health facilities. Additionally, with over 2 million Yemeni children out of school, the spread of severe malnutrition across the country, and ongoing conflict and violence, there has been a critical increase in trauma and poor mental health amongst children. Consequently, many Yemeni children have been stripped of their childhoods and are facing severe toxic-stress, which could lead to detrimental mental health disorders and illnesses in the future. Based on the report by Columbia University's Mailman School of Public Health, over 462,000 Yemeni children under the age of five are suffering from severe malnutrition, and over 1,500 Yemeni children have been forced into childhood recruitment [21]." As a result, there has been a widespread increase in fear, anxiety, anger, and insecurity amongst Yemeni children. These "minimal" and somewhat "normal" stressors can develop into severe mental illnesses and disorders such as depression, anxiety, and posttraumatic stress - disorders that could further strip the livelihoods of these vulnerable Yemeni children.

Many of the mental health predictions in Syria and Yemen have been based off of research and studies taken from past conflict-stricken populations in the Middle East. One post-war population based survey, analyzing the effects of conflict, war, violence, and human suffering on the mental health of 799 Afghans, found that $62 \%$ of the respondents showed signs of depression, $72.2 \%$ showed symptoms of anxiety, and $42 \%$ were found to show signs of post traumatic stress disorder. Additionally, the researchers found that respondents who showed significantly higher symptoms of depression, anxiety, or PTSD were more likely to have experienced a higher number of traumatic events [22]. Similarly, another post-war population based study, analyzing the effects of genocide, war, violence, and migration on the mental health of 45 Kurdish families who survived the military operation and genocide "Anfal" in Iraqi Kurdistan, found that PTSD was present in $87 \%$ of the children and $60 \%$ of their caregivers. After five years had passed since the genocide and atrocities, the Kurdish families who had taken refuge in displacement camps, especially the children, faced significant and severe mental distress [23]. This study further solidifies the correlation between conflict-based trauma and a poor state of men- tal health.

Since the late 1940's, the Palestinian population has constantly been exposed to violence and trauma, severe instability, poor healthcare, and inhumane living conditions, all of which have resulted in a significant and ongoing mental health crisis. A study by the Gaza Community Mental Health Program analyzed the mental health status of children between the ages of 10 to 19 . The study found that $32.7 \%$ of the children suffered from severe PTSD that required psychological intervention, $49.2 \%$ of the children were found to have moderate symptoms of PTSD, $15.6 \%$ showed signs of mild PTSD, and only $2.5 \%$ of the children showed insignificant signs of PTSD [24]. Additionally, a report by the Columbia Mailman School of Public Health, analyzing the effects of conflict-related trauma on the mental health of children be-tween the ages of 10 to 18 living in the Gaza Strip, noted that $99 \%$ of the children had suffered from severe humiliation, $97 \%$ had heard explosions, and $84 \%$ has seen shelling from tanks, artillery, and/or warplanes. The report then found that these events triggered severe symptoms of PTSD in $41 \%$ of the children studied and low-level symptoms of PTSD in 58\% of them, proving that traumatic and fearsome incidents, such as those mentioned in the report, contribute to the significant increase in psychological problems amongst children in the region. The report stated that "the types of symp-toms exhibited ranged from cognitive, emotional, and somatic to social and academic behavioral disorders. Other studies have shown that exposure to war and violence in 
early childhood has negative implications for a child's personality and psychological well-being later in life [21]."

A study by the Gaza Mental Health Center found that the most significant instances of trauma that children in Gaza are exposed to, include witnessing funerals (95\%), witnessing public shootings (83\%), direct view of and exposure to brutally injured and dead strangers $(67 \%)$, and seeing family members injured or killed $(62 \%)$. Other instances noted in comparative studies included the arrest and beating of relatives and neighbors, and the daily exposure to inhumane living conditions and life-threatening toxins. The study by the Gaza Mental Health Center, referenced above, correlated the unmistakable rise of PTSD levels to these traumatic exposures, finding that among children in the occupied territories of Palestine, 54\% suffer from severe PTSD and 33.5\% suffer from moderate PTSD [24]-concluding that nearly $85 \%$ of the children in the occupied territories of Palestine has suffered from some form of mild to severe PTSD.

Interestingly, most of the studies referenced above noted that the mental health of refugees significantly worsened upon migrating to camps or host countries. This proves that more often than not, the conditions in refugee camps and host countries offer a deplorable lifestyle that only exacerbates the traumas that refugees experienced at home. Refugee camps and host countries should offer a safe and humane environment for refugees to peacefully rebuild and resettle the lives that were forcefully stripped from them. However, research proves that this is currently not the case, as refugee camps have been found to offer unsanitary and inhumane conditions.

Many refugees face severe psychological and mental health disorders during the post-migration process. This surging mental health crisis is generally influenced by the adverse nature of the migratory experience. However, after fleeing conflict, war, malnutrition, and torture at home, refugees should be welcomed into camps and host countries that can provide psychological support, normalcy, and an opportunity for resettlement and hope in the future. During the migratory process, it may last days, weeks, or months, many refugees experience family separation, death, trauma, and chronic fear and anxiety. These inevitable aspects of the migratory process manage to contribute to the deteriorating state of mental health amongst refugees. Upon settling into refugee camps, refugees should be required to attend therapy sessions and mental health care facilities in order to ensure that they have not been greatly impacted by the traumas of conflict and the migratory process.

In many ways, the social adversity that refugees face upon resettlement can contribute to the increasing state of poor mental health. In refugee camps and host countries, refugees encounter incommodious language barriers that hold them back from normalcy, education, employment, income, and social acceptance. Many refugees are confronted with discrimination due to a common stigma against refugees and politics regarding the immigration process. Additionally, children and teen refugees are exceedingly prone to obesity due to the unhealthy and economical lifestyle that is promoted within refugee camps, and due to most refugees' inability to access proper and healthy foods that tend to be expensive. These conditions often contribute to low self-esteem, depression, and other mental illnesses that could become critical later in life. However, social adversities are not the sole cause of the mental health crisis in refugee camps. It has been noted that refugee camps facilitate inhumane and disturbing conditions, while providing very little health, better yet, mental health support or care. Nadmi Almoshmosh, a UK psychiatrist of Syrian origin who worked on the mental health needs of Syrian refugees in Jordan and Turkey, stated that "initially refugees felt that this would be a short ordeal. People were defiant, angry, and frustrated. Life was difficult in adjusting to the new reality of refugee life and its indignities.

With time there is now despair and hopelessness. Many cases of mental health problems continue to suffer in silence for reasons of stigma and also lack of trained mental health professionals to turn to. Many humanitarian agencies have lacked coordination amongst themselves and different approaches leading to less than ideal care [25]." As Almoshmosh noted, the camps provide insufficient care and inhumane conditions that worsen the psychological and overall mental health state of most refugees. Most of the camps lack running water in the bathroom facilities and provide refugees with filthy and unhygienic sinks and showers that could lead to a number of communicable viruses, infections, and a wide range of unaffordable and untreatable illnesses that strain their already arduous lifestyle. Additionally, most refugees are clustered into thin tents that provide insufficient heat during the extremely harsh winters. And to exacerbate the conditions, refugee camps provide unsafe and unprotected grounds that have resulted in a number of sexual assault and physical abuse cases-leaving most refugees in a state of constant fear, anxiety, and precaution [25]. These inhumane conditions vouch for a lifestyle of fear, instability, and hopelessness that contributes to the state of poor mental health amongst refugees.

Innocent refugees, who have faced inconceivable adversity and trauma, should be guaranteed the right to resettle under humane and livable conditions. In addition, refugee camps should be fully equipped with mental health facilities and professionals who can help to assure healing, resettlement, and growth. 


\subsection{The increasing rate of communicable and non-communicable diseases}

a. How have war, conflict, and migration increased the risk of communicable and non-communicable diseases amongst vulnerable populations in the Middle East?

b. What measures can be taken in order to effectively diminish the increasing spread of formerlyeradicated communicable diseases and the inauguration of life-threatening non-communicable diseases amongst conflict-stricken and refugee populations in the Middle East?

There has been a significant rise in the spread of communicable diseases and a notable increase in the inauguration of non-communicable diseases amongst refugee and conflict-stricken populations in the Middle East. As noted throughout this paper, refugees who have migrated to camps and host countries have been living under inhumane and sub-standard conditions, which have consequently turned the over-populated camps into "breeding grounds for a range of life-threatening diseases [26]." And although this trend has become apparent to non-governmental organizations and international bodies, there are very few measures being taken in order to prevent the rapid spread and inauguration of these chronic and life-threatening diseases. A number of these diseases are being transmitted through contaminated food and water, on-site pollution, unsanitary facilities, chemical toxins, armed conflict, and sexual abuse. The lack of humane and sanitary conditions, as well as the lack of law enforcement and protective measures by authorities to thwart off the rampant rise in sexual and physical abuse are contributing to the expedition of this chronic crisis. Even the United Nations has noted that the poor living conditions in host countries and refugee camps have contributed to the on-going and severe refugee health crisis [27]. Refugees, who have fled violence and war at home, should not have to face life-threatening conditions within the camps and host countries. According to a study by the UNHCR, "two-thirds of refugees across Jordan are now living below the national poverty line, and one in six Syrian refugee households is in abject poverty, with less than $\$ 40$ per person per month to make ends meet. Almost half of the households researchers visited had no heating, a quarter had unreliable electricity, and 20 per cent had no functioning toilet. Rental costs accounted for more than half of household expenditures, and refugee families were increasingly being forced to share accommodations with others to reduce costs [27]." Along with these hardships, most refugees are unable to access affordable health care, which has led to an increase in, what could have been, recoverable deaths and the proliferation of non-communicable diseases. With over one million Syrian refugees living in Jordanian refugee camps or urban housing, the overall health care system has not only become unaffordable but the entirety of the system is rapidly deteriorating. In 2012, the number of Physicians per 10,000 people in Jordan was 27.1, however, due to the influx of Syrian refugees, by 2014, the number of physicians per 10,000 people in Jordan decreased to 20.2. Additionally, in 2014, the Jordanian government discontinued its issue of free universal health care coverage to its citizens, including Syrian refugees. For the vast majority of Syrian refugees, who make less than \$2 per day, the foreigners fee at government-run clinics are unaffordable [27].

Many camps, host countries, and conflict-stricken regions also lack the necessary medications to properly treat life- threatening and chronic diseases. In a study done by notable physicians, Tala Al-Rousan, Zaker Schwabkey, Lara Jirmanus, and Brett D. Nelson, it was found that a majority of the refugees, living in the Zaatari Refugee Camp and the Azraq Camp in Jordan, specified that essential medicines for lifethreatening diseases were not available in the camp clinics [28]. With help from international bodies and non-governmental organizations, many life-saving medications could be directly delivered to these vulnerable populations at low costs. Simple immunization medications and disease therapies could save a number of refugees from excruciating and life-threatening diseases.

\subsubsection{Communicable diseases}

The spread and proliferation of communicable diseases amongst conflict-stricken populations and refugees in the Middle East has dramatically increased in recent years - the most prevalent of those diseases being cholera, malaria, hepatitis A, hepatitis E, tuberculosis, typhoid fever, HIV, and meningitis. Most of these diseases have advanced and spread as a result of unsanitary and inhumane conditions in refugee camps, host countries, and conflict-stricken regions. These vulnerable populations are constantly exposed to disease-contaminated foods and water, harmful toxins, pollution, overpopulation, and severe violence, which can easily lead to a number of life-threatening communicable diseases that are difficult to treat and control due to severe overpopulation and a substantial lack of overall medical care. Additionally, there has been a substantial decline in the vaccination coverage of treatable and once-eradicated diseases amongst refugee and conflict- stricken populations, which has resulted in the rapid reemergence of life-threatening diseases such as cholera and polio. A report by The Global Polio Eradication Initiative noted that "vaccination coverage in Syria is estimated to have dropped from $91 \%$ in 2010 to as low as $45 \%$ in some regions by 2013, indicating rapid collapse of immunization systems in conditions of war." The report also found that over half of the 1.8 million Syrian children born since the onset of the civil war in 2011 are un-immunized, making them exceedingly vulnerable to life-threatening diseases [29]. This in-crease in infectious diseases is not only 
related to the decline in crucial vaccinations, but it is also directly related to the inhumane conditions that refugee and conflict-stricken populations are forced to face. The World Health Organization predicts that over 7,600 Syrians are currently infected by the poliovirus due to viral food and water contamination, un-sanitary living conditions, and malnourishment within the country [29]. The report referenced above, by The Global Po lio Eradication Initiative, furthered WHO's statement by finding that "in Syria, raw sewage is pumped directly into the Euphrates River, which provides drinking and washing water to villages and chlorination to decontaminate the water has been discontinued since 2012 [29]." This contaminated water is directly related to a number of life-threatening cases of Polio and demonstrates the need for immediate care from international bodies and non-governmental organizations who can promote clean food and water enterprises, increased vaccination initiatives, and intensive sanitation efforts.

Similarly, in Yemen, the ever-growing cholera epidemic has become recognized as the largest outbreak in world history. According to the International Rescue Committee, the number of suspected cholera cases in Yemen reached over 1,000,000 in 2017 [30]-more than 2,000 of those infected with the disease have died and over 600,000 of the suspected cases have been reported to be children [31]. The relentless outbreak came about after airstrikes released garbage and sewage into prominent waterways, resulting in the spread of the waterborne virus. The country's constant state of violence, extreme unsanitary conditions, and collapsing health care system has contributed to further spreading the virus. Cholera is an easily preventable disease that can be suppressed and contained as long as food and water sources are sanitary and thoroughly disinfected. Yet, the conditions in Yemen are extremely harsh, with over 19.3 million Yemenis lacking access to clean water, simple food and water sanitation efforts may not be enough to contain the outbreak [32]. As Johns Hopkins professor, David Sack, stated, "a patient with cholera should never die [30]." It is crucial that international bodies and non-governmental organizations strive to suppress and contain this life-threatening, yet easily treatable, epidemic.

Additionally, there has been a significant increase in the rate of communicable diseases amongst refugees who have mi- grated to camps and host countries. Many refugees flee their home countries, not only to escape the sea of violence, but in order to avoid the infectious and life-threatening diseases that appear as a result of war. However, most refugees encounter these infectious diseases in refugee camps due to the unsanitary and inhumane living conditions [33]. These camps have become known as "breeding grounds" for infectious and life-threatening diseases. According to the UN-HCR, 60\% to $80 \%$ of all deaths amongst refugee populations are due to infections such as measles, malaria, respiratory infection, and diarrhea [34]. A report by the UNHCR also noted that "overcrowding and precarious situations in which the displaced people live increase the risk of death from communicable diseases." Along with this overpopulation, the "low vaccination coverage, poor access to fresh water and sanitation, limited healthcare services, and disruption of vaccine supply and distribution" has contributed to the spread of disease within refugee camps, host countries, and regions of instability [34]. Many refugees migrate to camps and host countries in order to regain stability, safety, and healthcare, however, in most cases, the camps and host countries provide unsanitary, inhumane, and substandard living conditions that often exacerbate the pre-existing critical health needs of refugees.

\subsubsection{Non-communicable diseases}

With the onset of the refugee crisis in the Middle East, there has been a significant increase in the inauguration of non-communicable diseases amongst refugee and conflict-stricken populations. And due to the mass influx of refugee populations, many host countries have found it difficult to respond to these taxing diseases. In Jordan, non-communicable diseases have become the leading causes of death. $76 \%$ of deaths amongst the Jordanian population, including the large majority of refugees who have immigrated there, can be attributed to non-communicable diseases [35]. As, many camps, clinics, and medical professionals are no longer able to provide the adequate medications, tools, or funding necessary to properly treat these costly and demanding diseases. "Traditionally, humanitarian responses focused on short-term control of communicable diseases, while the management of NCDs requires a long-term approach with sometimes complex and costly interventions [36]." However, as one of the leading causes of death amongst vulnerable refugee and conflict-stricken populations, non-communicable disease care must become a priority for non-governmental organizations, international bodies, and global healthcare systems.

"The World Health Organization estimates that $70 \%$ of deaths throughout the world are attributable to non-communicable diseases (NCDs), mainly in the form of cardiovascular diseases, diabetes, lung disease and cancer. Low and middle- income countries are particularly affected, with the risk of premature death-before the age of 70-caused by NCDs... Refugees and migrants suffering from NCDs are more vulnerable to the stresses of migration and the harsh conditions on migration routes, and suffer from a lack of regular access to suitable health care. For people living in crisis or emergency situations, the risk of 
exacerbating pre-existing conditions or suffering acute complications, is two to three times higher than it was beforehand [37]."

These high rates of non-communicable diseases amongst refugee and conflict-stricken populations can be attributed to poor diet and malnourishment, extreme poverty, severe and constant stress, unsanitary living conditions, lack of adequate medical care, injury, displacement, and constant exposure to chemical toxins and relentless conflict. According to a number of studies, an astonishing $19 \%$ to $46 \%$ of fatalities in "the top 5 source countries for refugees in 2015" were due to non-communicable diseases [38]. A recent report also found that $23 \%$ of Syrian refugees in Northern Jordan who were in need of noncommunicable disease care did not receive it and $61.5 \%$ of those refugees "cited provider cost as the main barrier." Additionally, the report found that $23.1 \%$ of refugees with regular medication needs interrupted their regularity due to the high-cost in medication and healthcare [36].

The World Health Organization recently estimated that in Yemen alone, over 35,000 people have been diagnosed with cancer-over 11,000 patients are diagnosed each year [39]. One of the many causes of this growing crisis is the Yemeni population's direct and constant exposure to toxic air and chemical warfare. The ongoing violence and conflict has contributed to the deterioration of the country's already minimal healthcare system. "Medical centers have been destroyed or are slowly losing the ability to treat people as shortages in medicines and equipment challenge the rapidly shrinking medical teams [40]." The remaining medical facilities are unable to afford or access the proper medical equipment and medications to treat life-threatening cases of non-communicable diseases. Yemeni cancer patients are "struggling to get treatment in a country where the economy and infrastructure have collapsed...most people can't afford the necessary medicines. The national Oncology Center in the Capital of Sanaa, which admits around 600 new cancer patients each month, only received one million dollars in funding last year - that's down from fifteen million previously. That money was mainly used to purchase chemotherapy medications and anti-cancer drugs for the centers across the country [39]." For many cancer patients in Yemen, the disease has become an inevitable death sentence, with most fearing that by the time they have access to the proper medical treatments; the cancer will have already spread through to the rest of their bodies. Prior to the ongoing conflict, most anticancer and chemotherapy drugs were provided by the state; however, now, medical facilities, both inside of Yemen and within the surrounding refugee camps, are primarily reliant on charity, grants, and donations provided by international bodies, non-governmental organizations, and wealthy business owners.

There has been a strong international focus on communicable diseases and acute infections amongst refugee and conflict-stricken populations, while those suffering from life-threatening, non-communicable diseases have painfully gone unnoticed. International bodies and non-governmental organizations must provide healthcare clinics in areas of conflict and refugee camps that contain the proper funding and medical equipment to treat these distressing, non-communicable diseases.

\subsection{The increasing rate of neonatal diseases and disorders}

a. How have war, conflict, and migration increased the risk of neonatal disorders, fetal malformations, and stillbirths amongst vulnerable populations in the Middle East?

b. What measures can be taken in order to effectively abate the increasing rate of neonatal disorders, fetal malformations, and stillbirths amongst conflict-stricken and refugee populations in the Middle East?

There has been a significant increase in the number of neonatal disorders and infant moralities amongst conflict-stricken populations and refugees in the Middle East. This trend is directly related to refugee and conflict-stricken populations' constant exposure to violence and conflict, harmful toxins, chemical warfare, life-threatening viruses, unsanitary conditions, severe poverty, malnutrition, and inadequate healthcare.

The Palestinian Population has seen a significant increase in the number of infant mortalities as a result of congenital anomalies, premature birth, extensive infections, inadequate neonatal care, pollution, and exposure to chemical toxins. This is further proved by the significant disparity in infant mortality rates between the occupied territories of Palestine and the surrounding Israel. In Israel, the infant mortality rate is nearly 3.5 deaths per 1,000 live births. While, in Palestine the infant mortality rate is about 15.8 deaths per 1,000 live births [41]. These statistics demonstrate the severe impact that conflict, poverty, and pollution have on the outcome of neonatal healthcare within a territory. There has also been a significant increase in malformations and the development of genetic disorders amongst Palestinian children in the occupied territories and refugee camps. This increase is directly associated with significant environmental changes and exposure to chemical warfare and harmful toxins. Following the onset of the Palestinian-Israeli conflict, the Palestinian territory has become extremely polluted as a result of the chemical toxins released by chemical warfare, air strikes, and bombs. These direct exposures to life-threatening pollution, air toxicity, and toxic remnants have further contributed to the country's neonatal health care crisis. In a comparative 
study, it was found that the leading cause of infant mortality in the Gaza Strip is congenital malformation. The study found a sizable increase in the prevalence of structural birth defects from 2006 to 2010, with 39.5 birth defects per 1,000 hospital admissions in 2006 to 63 birth defects per 1,000 hospital admissions in 2010 [42].

The rise of birth defects in the Palestinian territory is also directly related to the parent's exposure to chemical warfare such as the white phosphorus shelling attacks on the Gaza Strip [43]. A report published by the International Journal of Environmental Research and Public Health found that 27\% of parents with "birth defect children had declared exposure to white phosphorus." While only $1.7 \%$ of the parents who had declared to have been exposed to white phosphorus had birthed healthy children [44]. Another report stated that "the rubble containing war remnants is one of the permanent sources of contamination that persist after war, and toxicants and teratogens stable in the environment, such as metals, are associated with the weaponry. These contaminants, once consumed by mothers who were exposed to bombing and white phosphorus, are found specifically associated with premature and respectively malformed babies, who were contaminated in uteri. The incidence of the malformations in Gaza has increased compared to 1997, steadily since the first usage of military attacks by ground and air on Gaza at the second intifada. After Cast lead, when less ammunitions and less heavy bombs were used than since July 7, 2014, and less extensive destruction occurred, the contaminants were in the mothers' bodies and passed to the embryo and fetus, even when conceived 2 years after the attacks. In summary, we know already that military attacks are likely to have set an environmental load on the health of those not yet born, even of those not yet conceived, for a protracted time [45].

Similarly, there has been a significant rise in the number of neonatal deformities, premature births, and infant deaths in war-torn Yemen. Many scientists have directly associated this increase in neonatal complications to the toxic chemical warfare. An obstetrician at the Al-Rahma Hospital in Yemen, Wafa Al-Mamri, stated that "Fetal malformations could occur due to several reasons, including mothers' diseases and subsequent viral infection of the faction and/or poor nutrition. The strange thing is that the rate of fetal abnormalities is growing up and doctors cannot explain the causes, meaning that the phenomenon could be attributed to war and ordinances, given the fact that a great proportion of women with deformed fetuses hailed from bombarded areas in the provinces of Sa'adah, Sana'a, Ta'izz and Hudaydah [46]."

Refugees, who have migrated to camps, from conflict-stricken regions such as Syria and Yemen, are also seeing a rise in neonatal disorders and infant deaths. The same unsanitary and inhumane conditions, found in refugee camps, that resulted in the increased spread of communicable diseases have also directly contributed to the significant rise in neonatal complications amongst refugee populations. A mother's exposure to unsanitary water and food supplies can lead to physical malformations. However, many scientists are also seeing a rise in neurological malformations amongst newborns in refugee camps [47]. Some scientists and physicians have associated this increase to a lack of the vitamin folic acid [48]. As a result of malnutrition and poor food distribution within the refugee camps, many migrants lack the proper nutrients to ensure the full and healthy development of their fetuses. This increase in neonatal disorders can also be directly related to the lack of proper healthcare offered in host countries and refugee camps [49]. Many migrants have been noted to avoid medical facilities due to the hefty healthcare costs, resulting in significant birthing complications and newborn mortality rates [50].

Non-governmental organizations should ensure proper maternal health care systems within camps and host countries. Pregnant mothers should be provided with safe and sanitary facilities, as well as, the proper nutrients to ensure healthy fetal growth. Furthermore, host countries and refugee camps need to provide pregnant refugees with affordable health-care and should ensure that expecting-mothers check into maternal-care facilities regularly. No mother should fear hefty neonatal-care costs.

Additionally, non-governmental organizations and international peace-making bodies must ensure that the rules of war are obeyed during conflict. Throughout history, chemical warfare has proved detrimental to post-war generations. There is a direct correlation between exposure to chemical warfare and increased neonatal disorders, birth defects, and infant mortality rates. Future generations should not have to suffer from life-threatening birth defects and neonatal disorders as a result of avoidable chemical warfare.

\subsection{Recommendations}

An international effort to eliminate the negative stigma towards immigrants and the refugee crisis. Refugees are constantly confronted with marginalization and inhumane conditions due to the prejudice and discriminatory stigma regarding immigration and the refugee crisis [51]. This negative stigma denies refugees the opportunity to resettle and rebuild the lives that they lost due to conflict and displacement. International organizations and non-governmental bodies need to ensure that people understand the needs of refugees, who are simply in search of humanity, safety, healthcare, and shelter. With a larger percentage of those in favor of refugee-care and open borders, international bodies and governments will place more 
emphasis on refugee needs and healthcare. If a negative stigma surrounding the refugee crisis is maintained, then refugees will continue to receive inadequate healthcare, unsanitary facilities, and substandard living conditions. In order to completely tackle the refugee health crisis and provide refugee and conflict-stricken populations with hope and opportunity for the future, the citizens of host countries must treat refugees with fairness and respect. Politicians, news outlets, and non-governmental organizations could easily contribute to this effort by promoting immigration and refugee support efforts.

Stricter international policy regarding the use of toxic, life-threatening chemical weapons in areas of conflict. The use of chemical weapons in areas of conflict, directly impacts the lives of innocent civilians who come into contact with the chemical toxins. As, exposure to chemical weapons and warfare has proved to result in a number of life-threatening diseases, mental illnesses, birth defects, and infant mortalities. The use of chemical weapons is a notable war crime and international bodies and governments such as the UN should ensure that international governments obligate the rules of war and ensure that extensive measures are taken in order to prevent innocent civilian casualties and direct contact with harmful toxins.

Increased sanitation efforts in refugee camps and conflict-stricken regions. Any unsanitary and infected water or food sources should be cut off from distribution and supply and should be disinfected as soon as possible. Waterways and food sources should be regularly inspected for life-threatening bacteria and toxins. Additionally, all facilities in refugee camps should assume sanitary and humane conditions. Refugee camps should ensure working electricity and constant sanitation efforts in order to contain the spread of communicable diseases.

Access to affordable healthcare. Upon migrating, most refugees are confronted with extreme poverty. Thus, most refugees who are suffering from communicable or non-communicable diseases are unable to afford or access the proper medication and care. Governments and international bodies need to ensure that refugees living within their borders are receiving adequate healthcare services that are non-discriminatory and affordable. With over $70 \%$ of Syrian refugees under the poverty line, refugees must be provided with equitable access to healthcare and medical facilities [52].

A larger medical staff and effective medical training. Non-communicable diseases require a complex level of care and there should be specific nurses and medical professionals caring for those chronic-specific cases. There should also be communicable disease specialists and mental health professionals in every refugee camp and medical facility. With the influx of refugees, refugee camps require more than 5 or 6 general practice nurses and doctors. There is a desperate need for specialized doctors and nurses who are able to directly assist refugees with specific medical conditions.

An emphasis on education within refugee camps. After fleeing conflict-stricken regions, many children, teens, and adults are faced with a number of mental health disorders, as well as, poverty, language barriers, and occupational uncertainty. Amidst this state of fluctuation and unsettlement, it is crucial that refugees are continuing their education and furthering their hope for a better future. An entire generation of Middle Eastern children has not received proper education due to conflict and displacement. Dr.Bootheby, of Columbia University, found that "the exposure to toxic stress and the absence of children from school" can directly result in life threatening, non-communicable diseases and severe issues in adulthood. Access to education in refugee camps and conflict- stricken regions should be made a priority [53] in order to reinstate a sense of normalcy amongst children, en-sure that refugees have the opportunity to resettle and rebuild a better future, and prevent the rise in mental health diseases such as PTSD and depression.

Stricter vaccination requirements in refugee camps and conflict-stricken regions. In order to suppress the spread of communicable diseases, all refugees, especially children, must be vaccinated. Proper funding for medical equipment in clinics. Since, conflict-stricken countries and refugee camps do not have the proper funding and medical equipment to treat life-threatening, non-communicable diseases, many refugees are left with little hope for recovery. With proper funding for medications and medical equipment, thousands of refugees who are suffering from life-threatening communicable and non-communicable diseases can receive life-saving treatment and care.

Safety protocols and protective measures should be enforced within refugee camps. The rise in mental health disorders and the spread of communicable diseases, such as HIV and AIDS, are directly related to the prevalence of sexual assault and abuse within refugee camps. Safety within refugee camps needs to be ensured in order to prevent this increase in sexual assault and abuse cases.

\section{CONCLUSION}

The overall health status of refugees and conflict-stricken populations in the Middle East is an utter reflection of the poor social, political, and economic measures taken by international bodies, non-governmental organizations, and political spheres in attempts to tackle the growing refugee crisis. Although, there is a global effort in contribution to the refugee crisis, there is still a lack of support from 
politicians and international bodies-whose simple gestures have the ability to save millions of refugees who are desperately in need of humanity, safety, shelter, and proper healthcare. All of the findings gathered within this paper, characterize the holistic medical and socials needs of vulnerable refugee and conflict-stricken populations, such as fundamental vaccination initiatives, sanitary facilities, affordable healthcare, education, and access to life-saving medications. These findings also distinguish the inherent need for international governments and politicians to recognize the immense impact that chemical warfare and closed borders can have on millions of innocent civilians who are simply in search of healthcare and a safe home. International bodies and non-governmental organizations must compromise in building policies that will naturally protect the lives of the world's most vulnerable populations. If the refugee health crisis is not tackled immediately, an entire generation of young people will face unimaginable hardships and very little hope for the future. Refugees and conflict-stricken populations are simply in search of the hope, healthcare, humanity, and livelihood that were forcefully stolen from them. Everyone inherently de-serves access to proper healthcare, humane conditions, and inalienable human rights. International bodies and non-governmental organizations must ensure that refugees are given the opportunity to survive.

\section{REFERENCES}

[1] P. Kingsley, "What caused the refugee crisis? You asked Google - here's the answer | Patrick Kingsley," The Guardian, 09- Dec-2015. [Online]. Available: https://www.theguardian.com/commentisfree/2015/dec/09/whatcaused-the-refugee-crisis-google.

[2] "UN: World facing greatest humanitarian crisis since 1945," BBC News, 11-Mar-2017. [Online]. Available: https://www.bbc.com/ news/world-africa-39238808.

[3] K. Abbasi, K. Patel, and F. Godlee, "Europe's refugee crisis: an urgent call for moral leadership,” BMJ, 2015.

[4] "World Report 2018: Rights Trends in Syria," Human Rights Watch, 18-Jan-2018. [Online]. Available: https://www.hrw.org/world- report/2018/country-chapters/syria.

[5] C. Carafice, "Where Do We Go From Here? The Story of Syria's Public Health System," Middle East Studies Center, 17- Oct-2017. [Online]. Available: https://mesc.osu.edu/blog/where-do-we-go-here-story-syrias-publichealth-system.

[6] M. Kherallah, Z. Sahloul, G. Jamil, T. Alahfez, and K. Eddin, "Health care in Syria before and during the crisis," Avicenna Journal of Medicine, vol. 2, no. 3, p. 51, 2012.

[7] Charlie Cooper @ charliecooper8, "Syria in crisis: Country's healthcare system is 'going backwards in," The Independent, 26-Dec- 2013. [Online]. Available: https://www.independent.co.uk/news/world/middle-east/syria-incrisis-countrys-healthcare-system-is- going-backwards-in-time-at-a-rate-of-a-decade-a-month-9025319.html.

[8] "Eastern Mediterranean Region," World Health Organization. [Online]. Available: http://www.emro.who.int/syr/information-re- sources/.

[9] A. Baker, "In Syria, Three Years of War Take a Toll," Time, 14-Mar-2014. [Online]. Available: http://time.com/24741/the-cost-of- war-syria-three-years-on/.

[10] "The Visible Impacts of the Syrian War May Only be the Tip of the Iceberg," World Bank, 10-Jul-2017. [Online]. Available: https://www.worldbank.org/en/news/press-release/2017/07/18/the-visible-impacts-of-the-syrian-warmay-only-be-the-tip-of-the-ice- berg.

[11] N. Muaddi and B. Wehelie, "Yemen: 2 years, 50,000 casualties and 1 disastrous food crisis," CNN, 25-Mar-2017. [Online]. Avai- lable: https://www.cnn.com/2017/03/25/middleeast/yemen-war-2-years-trnd/index.html.

[12] "Yemen: Tackling the world's largest humanitarian crisis | UN News," United Nations, 24-Sep-2018. [Online]. Available: https:// news.un.org/en/story/2018/09/1020232.

[13] O. Coletta, "Refugee Camps: Poor Living Conditions and their Effects on Mental Health," Refugee Mental Health, 28-Mar-2018. [Online]. Available: https://sites.duke.edu/refugeementalhealth/2018/03/27/refugee-camps-poorliving-conditions-and-their-effects- on-mental-health/.

[14] Lizzie Dearden @lizziedearden, “After allowing thousands of refugees to drown, Europe is now letting them freeze to death," The Independent, [Online]. Available: https://www.independent.co.uk/news/world/europe/europe-refugees-freeze-to- death-hypothermia-bulgaria-athenscold-weather-serbia-sleeping-rough-a7520106.html.

[15] G. Hassan, P. Ventevogel, H. Jefee-Bahloul, A. Barkil-Oteo, and L. J. Kirmayer, "Mental health and psychosocial wellbeing of Syrians affected by armed conflict," Epidemiology and Psychiatric Sciences, vol. 25, no. 2, pp. 129$141,2016$.

[16] International Organization for Migration, "Jordan and Lebanon: Psychological distress common among Iraqi refugees, IOM study finds-Jordan,” ReliefWeb, 04-Mar-2008. [Online]. Available: 
https://reliefweb.int/report/jordan/jordan-and-lebanon-psychologi- cal-distress-common-among-iraqi-refugees-iomstudy-finds.

[17] R. Shaikh-Lesko, "Children Face The Greatest Danger From Chemical Weapons," NPR, 09-Apr-2018. [Online]. Available: https://www.npr.org/sections/goatsandsoda/2018/04/09/600833043/children-face-the-greatest-dangerfrom-chemical-weapons.

[18] World Health Organization, M. V. Ommeren, and S. Saxena, "Mental Health of Populations Exposed to Biological and Chemical Weapons ," pp. 1-8, 2005.

[19] D. Mosher, "A gas attack reportedly killed men, women, and children in Syria - here's why the deadly chemical feels like 'a knife made of fire' in your lungs," Business Insider, 10-Apr-2018. [Online]. Available: https://www.businessinsider.com/douma-syria-sarin- chlorine-gas-attacks-2018-4.

[20] Save the Children, N. Janati, and E. Taylor, "New Study Documents Psychological Horrors of Six-Year War on Syrian Children," Save the Children, 06-Mar-2017. [Online]. Available: https://www.savethechildren.org/us/aboutus/media-and-news/2017-press-re- leases/new-study-documents-psychological-horrors-of-six-year-war-on-syr.

[21] SANA'A Center for Strategic Studies Columbia University Mailman School of Public Health, F. Al-Ammar, W. Alhariri, T. Al- Ganad, S. Knuckey, R. S. Sawhney, S. Girijashankar, N. R. Rajshekhar, D. Tan, J. Zheng, and L. Stark, "the impact of war on mental health in yemen: a neglected crisis," pp. 1-13, 2017.

[22] W. F. Scholte, "Mental Health Symptoms Following War and Repression in Eastern Afghanistan," Jama, vol. 292, no. 5, p. $585,2004$.

[23] A. Ahmad, M. A. Sofi, V. Sundelin-Wahlsten, and A.-L. V. Knorring, "Posttraumatic stress disorder in children after the military operation 'Anfal' in Iraqi Kurdistan," European Child \& Adolescent Psychiatry, vol. 9, no. 4, pp. 235-243, 2000.

[24] R. S. Murthy, R. Lakshminarayana, and The World Psychiatric Association, "Mental health consequences of war: a brief review of research findings," World Psychiatry, Feb. 2006.

[25] M. T. Abou-Saleh and P. Hughes, "Mental health of Syrian refugees: looking backwards and forwards," The Lancet Psychiatry, vol. 2, no. 10, pp. 870-871, 2015.

[26] V. Sinha, "Refugee Camps Spread Life-Threatening Diseases - World," ReliefWeb, 18-Sep-2012. [Online]. Available: https://re- liefweb.int/report/world/refugee-camps-spread-life-threatening-diseases.

[27] United Nations, "UNHCR study shows rapid deterioration in living conditions of Syrian refugees in Jordan," UNHCR, 14- Jan-2015. [Online]. Available: http://www.unhcr.org/en-us/news/press/2015/1/54b635b49/unhcrstudy-shows-rapid-deterioration- living-conditions-syrian-refugees.html.

[28] T. A. Rousan, Z. Schwabkey, L. Jirmanus, and B. D. Nelson, "Health needs and priorities of Syrian refugees in camps and urban settings in Jordan: perspectives of refugees and health care providers," Eastern Mediterranean Health Journal, vol. 24, no. 03, pp. 243-253, 2018.

[29] S. L. Sharara and S. S. Kanj, "War and Infectious Diseases: Challenges of the Syrian Civil War," PLoS Pathogens, vol. 10, no. 11, Nov. 2014

[30] A. Erickson, "1 million people have contracted cholera in Yemen. You should be outraged.," The Washington Post, 22-Dec-2017. [Online]. Available: https://www.washingtonpost.com/news/worldviews/wp/2017/12/21/one-millionpeople-have-caught-cholera-in- yemen-you-should-be-outraged/?utm_term=.2d83d3eeab2b.

[31] Save the Children, "Yemen: Cholera Outbreak Now Largest and Fastest on Record, 600,000 Children Infected by Christmas - Yemen," ReliefWeb, 12-Oct-2017. [Online]. Available: https://reliefweb.int/report/yemen/yemencholera-outbreak-now-largest-and- fastest-record-600000-children-infected.

[32] Unicef, "Yemen," UNICEF Yemen - What we do - Water, Sanitation and Hygiene. [Online]. Available: https://www.unicef.org/yemen/activities_11440.html.

[33] R. Ozaras, H. Leblebicioglu, M. Sunbul, F. Tabak, I. I. Balkan, and M. Yemisen, "The Syrian conflict and infectious diseases," Expert Review of Anti-infective Therapy, vol. 14, no. 6, pp. 547-555, Apr. 2016.

[34] M. Snyder, "Displaced Populations and the Threat of Disease," Outbreak Observatory, 04-Jan-2018. [Online]. Available: https:// www.outbreakobservatory.org/outbreakthursday-1/1/4/2018/displaced-populations-and-thethreat-of-disease.

[35] World Health Organization, "WHO country cooperation strategy at a glance: Jordan," World Health Organization, 2018. [Online]. Available: https://apps.who.int/iris/handle/10665/136901.

[36] M. Rehr, M. Shoaib, S. Ellithy, S. Okour, C. Ariti, I. Ait-Bouziad, P. V. D. Bosch, A. Deprade, M. Altarawneh, A. Shafei, S. Ga- bashneh, and A. Lenglet, "Prevalence of non-communicable diseases and access to care among noncamp Syrian refugees in northern Jordan," Conflict and Health, vol. 12, no. 1, Jul. 2018.

[37] E. Martinez, "NCDs in refugees and migrants - the hidden crisis," World Cancer Research Fund International, 19Sep-2016. [Online]. Available: https://www.wcrf.org/int/blog/articles/2016/09/ncds-refugees-and-migrants-hiddencrisis.

[38] S. Sethi, R. Jonsson, R. Skaff, and F. Tyler, "Community-Based Noncommunicable Disease Care for Syrian Refugees in Leba- non,” Global Health: Science and Practice, vol. 5, no. 3, pp. 495-506, 2017. 
[39] "Cancer patients-the other victims of Yemen's war," Reuters, 24-Aug-2018. [Online]. Available: https://www.reuters.com/video/ 2018/08/24/cancer-patients-the-other-victims-of-yem?videoId=457678465.

[40] M. Jamjoom, "How Yemen's war is affecting cancer patients," News | Al Jazeera, 28-Feb-2018. [Online]. Available:https://www.aljazeera.com/news/2018/02/yemens-war-affecting-cancer-patients-180228124340407.html.

[41] L. Draper, "Gaza Infant Mortality Rate Increases for First Time in 50 Years," Newsweek, 16-May-2017. [Online]. Available: https://www.newsweek.com/gaza-infant-mortality-rategazainfant-mortality-rateunrwaunited-nationsrelief-601487.

[42] Y. Abed, N. Al Barqouni, A. Naim, and P. Manduca, "comparative study of major congenital birth defects in children of 0-2 years of age in the gaza strip, palestine," International Journal of Development Research, vol. 4, no. 11, pp. 2319-2323, Nov. 2014.

[43] A. Naim, H. A. Dalies, M. E. Balawi, E. Salem, K. A. Meziny, R. A. Shawwa, R. Minutolo, and P. Manduca, "Birth Defects in Gaza: Prevalence, Types, Familiarity and Correlation with Environmental Factors," International Journal of Environmental Research and Public Health, vol. 9, no. 5, pp. 1732-1747, 2012.

[44] F. De Ponte, "New study finds strong correlation between birth defects and white phosphorus exposure of parents," Middle East Children's Alliance, 07-May-2012. [Online]. Available: https://www.mecaforpeace.org/new-studyfinds-strong-correlation-between- birth-defects-and-white-phosphorus-exposure-of-parents/.

[45] I. Abuelaish, "We are both doctors: a Palestinian doctor writes to an Israeli colleague," The BMJ, 13-Aug-2014. [Online]. Avai- lable: https://www.bmj.com/content/349/bmj.g5106/rapid-responses.

[46] PressTV, "More Yemeni women delivering stillborns, babies with birth defects: Medics," PressTV, 29-Jun-2016. [Online]. Available: https://www.presstv.com/Detail/2016/06/29/472715/Yemen-women-stillbirths-deformedbabies-Saudi-Arabia.

[47] [47]. M. M. V. D. Berg, H. H. Madi, A. Khader, M. Hababeh, W. A. Zeidan, H. Wesley, M. A. El-Kader, M. Maqadma, and A. Seita, "Increasing Neonatal Mortality among Palestine Refugees in the Gaza Strip," Plos One, vol. 10 , no. $8,2015$.

[48] A. Czeizel, I. Dudás, A. Vereczkey, and F. Bánhidy, "Folate Deficiency and Folic Acid Supplementation: The Prevention of Neu- ral-Tube Defects and Congenital Heart Defects," Nutrients, vol. 5, no. 11, pp. 4760-4775, 2013.

[49] Z. Şimşek, N. Y. Doni, N. G. Hilali, and G. Yildirimkaya, “A community-based survey on Syrian refugee women's health and its predictors in Şanliurfa, Turkey," Women \& Health, vol. 58, no. 6, pp. 617-631, 2017.

[50] J. Dejong, H. Ghattas, H. Bashour, R. Mourtada, C. Akik, and A. Reese-Masterson, "Reproductive, maternal, neonatal and child health in conflict: a case study on Syria using Countdown indicators," BMJ Global Health, vol. 2, no. 3, 2017.

[51] E. Montgomery and A. Foldspang, "Discrimination, mental problems and social adaptation in young refugees," The European Journal of Public Health, vol. 18, no. 2, pp. 156-161, 2007.

[52] S. R. Sirin, L. Rogers-Sirin, and National Center on Immigrant Integration Policy, "The Educational and Mental Health Needs of Syrian Refugee Children," pp. 1-27, Oct. 2015.

[53] Columbia Mailman School of Public Health, "Strengthening the Response to the Syrian Refugee Crisis." [Online]. Available: https://www.mailman.columbia.edu/become-student/departments/population-and-family-health/newsand-events/family- news-2015-2016-0.

\section{BIOGRAPHY OF AUTHOR}

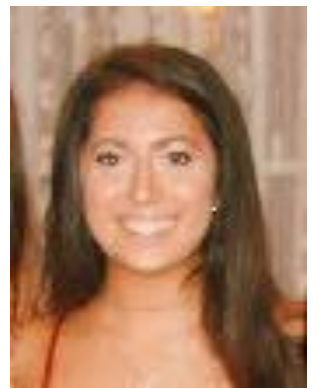

Selma Nouri will be a freshman at the University of Virginia this coming fall. Throughout high school, Selma dedicated her time to tackling the refugee health crisis by actively conducting refugee health research at local universities and by founding RISE (Refugee Inspirational Support Effort), a nonprofit organization. RISE aims to respond to the global refugee health crisis by providing refugees in Lebanon and Greece with vocational supplies and passion projects, such as musical instruments, art supplies, and sports equipment, in order to curb the rise in mental illness by establishing hope and humanity through passion and skill. Selma was a winner of the 2018 T-Mobile Changemaker Challenge for the founding and work of her nonprofit RISE. In college, Selma hopes to continue pursuing efforts towards tackling the refugee health crisis through research and activism. 